\title{
Tracheostomy Site Bleeding
}

National Cancer Institute

\section{Source}

National Cancer Institute. Tracheostomy Site Bleeding. NCI Thesaurus. Code C78648.

Bleeding from the tracheostomy site. 